\title{
Inflammatory bowel disease in developing tropical countries: abdominal pain caused by Ascaris lumbricoides diagnosed with single-balloon enteroscopy
}

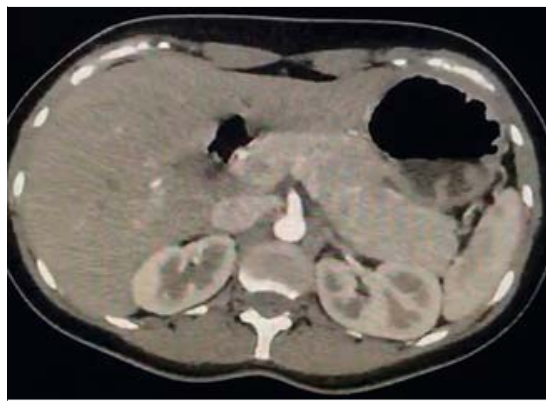

- Fig. 1 Contrast-enhanced computed tomography showing a diffusely enlarged pancreas.

A 36-year-old woman with no significant medical history presented with abdominal pain. She was admitted to emergency. An upper endoscopy was performed showing erosive gastritis and duodenitis. She was discharged with a proton pump inhibitor (PPI) without improvement. A computed tomograph (CT) and magnetic resonance imaging (MRI) cholangiopancreatography were performed; enlargement of the pancreas suggestive of autoimmune pancreatitis was observed ( Fig.1) but serum IgG4 levels were normal. She was referred to our hospital. Biochemical analysis showed blood eosinophilia. An expert radiologist reviewed the previous imaging studies and confirmed the suspicion of autoimmune pancreatitis, but segmental jejunal wall thickening was observed. Endoscopic ultrasound (EUS) was done, ruling out autoimmune pancreatitis. Because of previous findings in MRI, MRI enterography was indicated and multiple focal small bowel-wall thickening areas were observed (> Fig. 2) with a presumptive diagnosis of Crohn's disease. A single-balloon enteroscopy (SBE) was carried out for tissue samples. During SBE, a roundworm was identified ( $\triangleright$ Video 1 ) and extracted ( $>$ Fig. 3 ). It was finally identified as Ascaris lumbricoides. Oral albendazole

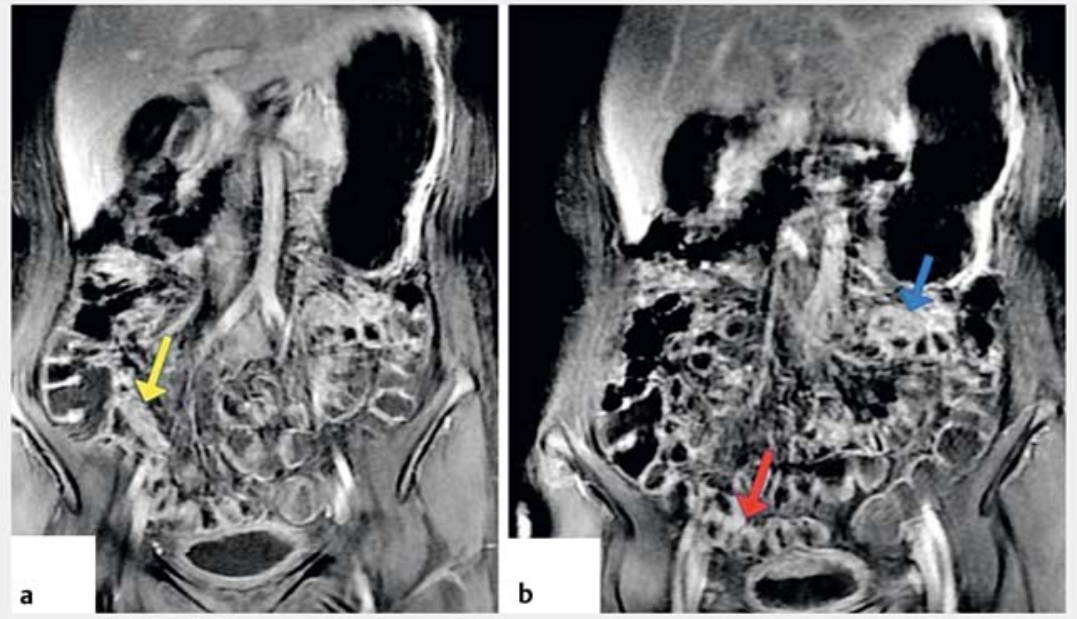

- Fig. 2 Magnetic resonance enterography showing (a) wall thickness of the terminal ileum (yellow arrow), (b) wall thickness of the jejunum (blue arrow) and distal ileum (red arrow).

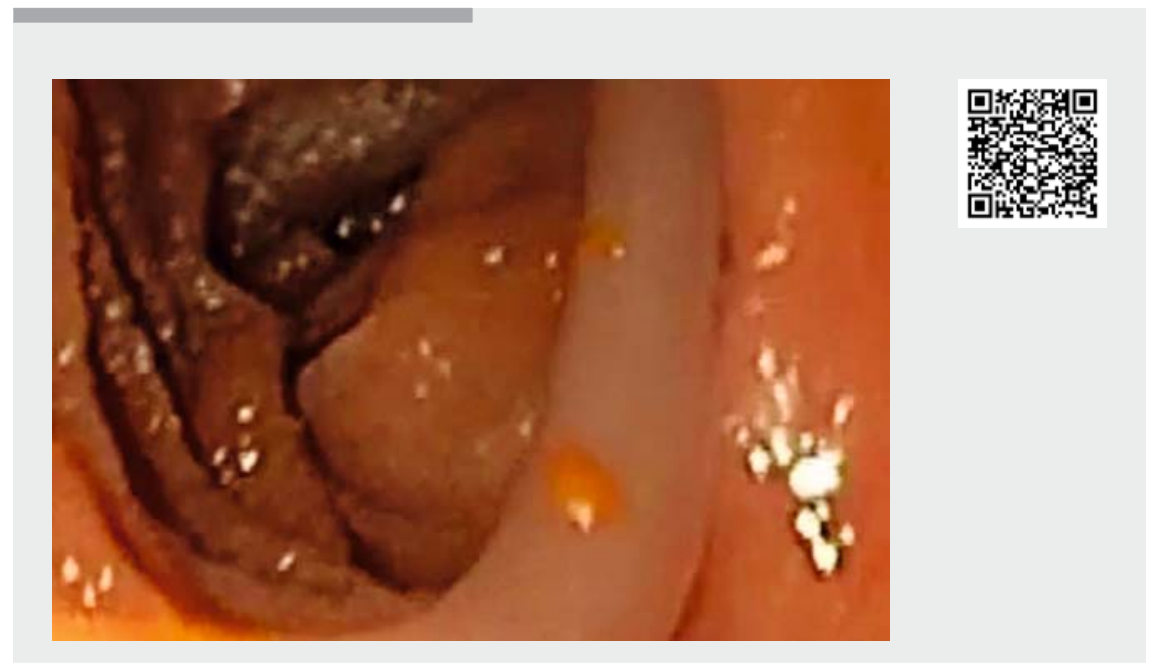

$\checkmark$ Video 1 Roundworm identified and extracted with a snare from the jejunum during single-balloon enteroscopy.

therapy was prescribed. The abdominal pain resolved after treatment.

Ascaris lumbricoides is an intestinal roundworm and is one of the most common helmintic human infections world- wide, especially in developing tropical countries. Infection usually occurs via ingestion of contaminated water or food. Adult worms inhabit the lumen of the small intestine, usually the ileum or jeju- 


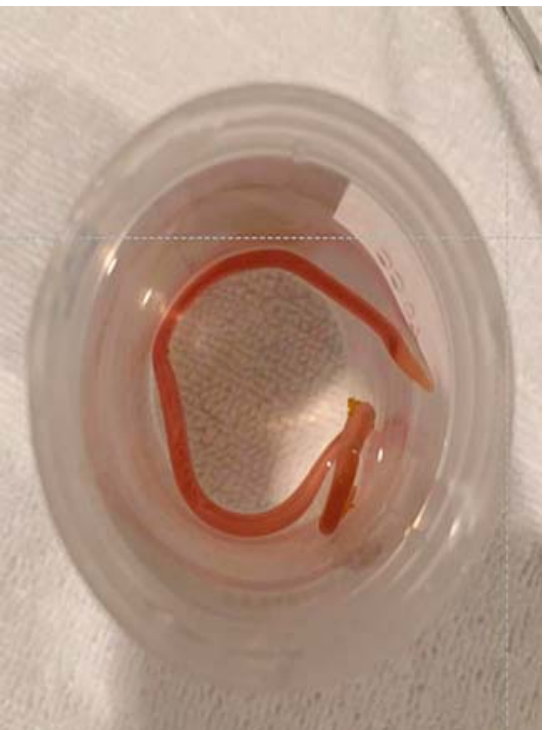

- Fig. 3 Roundworm extracted from the patient's jejunum, finally identified as Ascaris lumbricoides.

num [1]. Although infections are usually asymptomatic, the patient could present without specific signs and symptoms or in some cases with severe complications such as intestinal obstruction, gastrointestinal hemorrhage, perforation, pancreatitis, or cholangitis [2]. Epigastric and recurrent abdominal pain has been reported $[2,3]$. In the presence of abdominal pain and eosinophilia in the setting of a developing-country resident, a parasitic infection would have been suspected. There are only two prior reports of intestinal ascariasis diagnosed by double-balloon enteroscopy (DBE) $[4,5]$. In general, in symptomatic patients treatment with antihelmintic drugs is advised [1].

Endoscopy_UCTN_Code_CCL_1AC_2AG
The authors declare that they have no conflict of interest.

\section{The authors}

Alejandra Tepox-Padrón ${ }^{1}$, Melanie Figueroa ${ }^{2}$, Norberto Sánchez-Fernández ${ }^{3}$, Félix I. TellezAvila ${ }^{1}$

1 Department of Endoscopy, Instituto Nacional de Ciencias Médicas y Nutrición Salvador Zubirán, Mexico City, Mexico

2 Gastroenterology Department, Medica Sur Clinic and Foundation, Mexico City, Mexico

3 HPB Clinic, Hospital Ángeles de Puebla, Puebla, México

\section{Corresponding author}

\section{Félix I. Téllez-Ávila, MD}

Endoscopy Department, Instituto Nacional de Ciencias Médicas y Nutrición Salvador Zubirán, Avenida Vasco de Quiroga No. 15, Colonia Belisario Domínguez Sección XVI, Delegación Tlalpan C.P. 14080, Mexico City, México

Fax: +52-55-5487-0900

felixtelleza@gmail.com

\section{References}

[1] Bethony J, Brooker S, Albonico M et al. Soiltransmitted helminth infections: ascariasis, trichuriasis, and hookworm. Lancet 2006; 367: 1521-1532

[2] Uysal E, Dokur M. The helminths causing surgical or endoscopic abdominal intervention: a review article. Iran J Parasitol 2017; 12: $156-168$

[3] Schulze SM, Chokshi RJ, Edavettal M et al. Acute abdomen secondary to ascaris lumbricoides infestation of the small bowel. Am Surg 2005; 71: 505-507
[4] Walter BM, Born P, Winker ]. Ascaris lumbricoides causing obscure gastrointestinal bleeding detected by double-balloon enteroscopy. Endoscopy 2015; 47 (Suppl. 01): E354-355

[5] Hashimoto R, Matsuda T. Intestinal ascariasis detected by double-balloon enteroscopy. Dig Endosc 2017; 29: 387-388

\section{Bibliography}

Endoscopy 2021; 53: E359-E360

DOI 10.1055/a-1294-9555

ISSN 0013-726X

published online 19.11.2020

(C) 2020. Thieme. All rights reserved.

Georg Thieme Verlag KG, Rüdigerstraße 14,

70469 Stuttgart, Germany

\section{ENDOSCOPY E-VIDEOS}

https://eref.thieme.de/e-videos

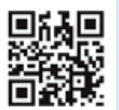

Endoscopy E-Videos is a free access online section, reporting on interesting cases and new

techniques in gastroenterological endoscopy. All papers include a high quality video and all contributions are freely accessible online.

This section has its own submission website at https://mc.manuscriptcentral.com/e-videos 